\title{
Optimization and Crashworthiness Investigation of Empty and Aluminium Foam Filled Square Tubes
}

\author{
Rana Pratap Singh ${ }^{*}$, Puneet Pawar ${ }^{2}$, Gaurav Kumar Gupta ${ }^{3}$ \\ 1 Masters student, IIT Gandhinagar, India. \\ 2 Masters student, IIIT Jabalpur, India. \\ ${ }^{3}$ Scientist, CSIR-AMPRI, Bhopal. \\ *Corresponding author. Tel.: +91-9806684519; email: rana.singh@iitgn.ac.in \\ Manuscript submitted October 21, 2016; accepted March 29, 2017. \\ doi: 10.17706/ijmse.2017.5.2.69-78
}

\begin{abstract}
Foam-filled thin-walled structures have drawn considerable attention and been widely applied in automotive and aerospace industries for their significant advantages in a high energy absorption and light weight. Recently the application of foam filled square tube in automobile industries has taken hike because of crashworthiness characteristic of foams. In the present study, energy absorption capacity of the empty (aluminum and mild steel) and foam in-filled (various aluminum alloys) square tubes have been numerically evaluated under car hitting condition. The finite element method (FEM) is applied in modeling the empty and foam-filled square tubes. The results show that the foam-filled square tubes have outstanding energy absorption characteristics under all the conditions considered. Based on the study results, best combination of materials in shell column wall and in-filled foam has been recommended.
\end{abstract}

Keywords: Square tube, in-filled foam, aluminum, FEM, energy absorption

\section{Introduction}

Closed cell foamed aluminium is a macro-composite material consisting of an aluminium alloy matrix, usually discontinuously reinforced with various ceramic particulates and closed pores filled with gas distributed throughout the matrix. This unique structure possesses an unusual combination of properties such as low density, high weight specific stiffness, extraordinary energy absorption and remarkable vibration attenuation, important for a number of engineering applications. Aluminium foams are also nonflammable, ecologically harmless and easily recyclable. In recent years, the use of metallic foams as a structural component has increased immensely because of its lightweight and high energy absorption capacity [1]. Uses of metallic in-filled foams in sacrificial square tubes are one of the most important applications where it absorbs the deformable energy of automotive component. A square tube is a component which is used in the frontal crash zone, inserted in-between chassis and the bumper. A square tube transfers the kinetic energy into deformation energy in such a controlled manner so that it retains sufficient survival space for the protected components and keeps the forces and accelerations on the following component at lower magnitude [2].

In the past, several researchers tried to understand the deformation behavior of empty and foam in-filled structures using both experimental and numerical techniques. Meguid et al. [3] and Hanssen et al. [4]-[7] carried out the experimental studies on the compressive behavior of empty and foam in-filled square and circular columns. Wang et al. [8] carried out extensive theoretical studies to predict the crushing behavior 
of empty and foam in-filled crash structures. Webb et al. [9] and Santosa et al. [10] carried out the finite element simulation of square and circular tube under static and dynamic loading to study their crashworthiness. Huang et al. [11], Hanssen et al. [12], Guo et al.[13] and Santosa et al.[14] investigated both experimentally and numerically the crushing behavior of empty and different aluminum foam in-filled tubes. It is reported that the crushing characteristics of a thin-walled column are improved dramatically by in-filling it with aluminum foam. Recently, Santosa and Wierzbicki [15]-[17] carried out numerical investigations on the effect of aluminum foam in-filling of thin-walled prismatic columns under axial crushing, torsion and bending. Abramowicz and Wierzbicki [18] developed an approximate solution to the problem of axial crushing of foam in-filled columns. The comparison of crashworthiness in aluminum infilled foams in particular with Al-2104 alloy and mild steel column material has not been reported.

In the present numerical study, the response of these materials in a square tube subjected to the energy corresponds to a car accident has been studied. The objective of the work is to analyze the crashworthiness of the square tube in-filled with different aluminum based foams, which is measured in terms of energy absorption during a car accident. In the present work, three dimensional (3D) FEM models of square tubes have been created which is subject to unidirectional compression loading of such an order of magnitude replicating the situation of a $1000 \mathrm{~kg}$ weight car moving with a $36 \mathrm{~km} / \mathrm{hr}$ speed. The empty square tubes models of aluminum alloy (Al 2014) and mild steel (MSrst37) shell column materials were studied for its crashworthiness. In other cases, these two shell columns are in-filled with different aluminum foams. The material properties of foams considered in the present study are given in Table 1. Metallic foams having approximately same relative densities are taken from the available literature. The four foams considered in the present study are Aluminum-Magnesium based ( $\mathrm{ALSi}{ }_{8} \mathrm{Mg}$ ), Aluminum-Silicon Carbide based (CYMAT AlSIC), Aluminum based (Duocel Al-6106-T6) with two different relative densities (Table 1). Finally, recommendations have been made based on the present study for using better material in empty and foam in-filled square tube which can absorb higher energy and show better deformation pattern under the car hitting situation. The present study is further extended to study the effect of friction coefficient between the shell column wall and the in-filled foam in the square tube.

\section{Experimental Testing and Finite Element Model of Empty and Foam Filled Square Tubes}

\subsection{Experimental Details}

\subsubsection{Aluminum Foam Making Technique}

Aluminum alloys have been foamed by mixing into them a foaming agent that releases gas when heated. The widely used foaming agent Titanium Hydride $\left(\mathrm{TiH}_{2}\right)$ begins to decompose into Ti and gaseous $\mathrm{H}_{2}$ when heated above about $465^{\circ} \mathrm{C}$. By adding Titanium Hydride particles to aluminum melt, large volume of hydrogen gas are rapidly produce, creating bubbles that can lead to closed cell foam, provided foam drainage is sufficiently slow, which requires a high melt viscosity. The process begins by melting aluminum and stabilizing the melt temperature between $670^{\circ} \mathrm{C}$ and $690^{\circ} \mathrm{C}$. Its viscosity then rises by adding $1-2 \%$ of calcium, which rapidly oxidizes, and forms finely dispersed $\mathrm{CaO}$ and $\mathrm{CaAl}_{2} \mathrm{O}_{4}$ particles. The melt then aggressively stirred and $1-2 \%$ of $\mathrm{TiH}_{2}$ has added in the form of 5-20 $\mu \mathrm{m}$ diameter particles. As soon as these are dispersing in the melt, the stirring system is withdrawn, and foam allowed forming above the melt.

\subsubsection{Specimen Preparation}

The square tubes of dimension $40 \mathrm{~mm}$ x $40 \mathrm{~m}$ and of thickness $1.4 \mathrm{~mm}$ were selected for the study. Five test samples were cut from each tubes of respective material and machined to a length of $150 \mathrm{~mm}$ each. Out of these ten samples, four Al2014 tubes and four MSrst37 tubes were filled with four different foams and the remaining each one of it were left empty. 


\subsubsection{Experiment}

Compression tests of all test specimen and foams were carried out at CSIR-AMPRI Bhopal using Universal Testing Machine (Instron model no. 8801) at room temperature under displacement controlled mode. The experiments were terminated manually when the specimens have crushed to beyond $100 \mathrm{~mm}$ from its initial length. The deformation pattern is observed. The load versus displacement curves is plotted and the energy absorbed during the compression process is calculated. The comparison is made between the empty and foam filled tubes. The stress-strain curves for all foams were obtained from the compression test. The stress strain curve for the foams is shown in Fig. 1. It shows that ALF 2 foam has a considerable elastic region while, ALF 1 has negligible elastic region. However, the plateau regions for all foams are spread till the strain of $0.6-0.8$ from where it starts densifying. Compression results were found to be in agreement with ALSi8Mg foam [13] , CYMAT Al-SIC foam [21] , Duocel Al-6106-T6 foam, 7.56 \% relative density1 [23] and Duocel Al-6106-T6 foam, $8.7 \%$ relative density [23] foam compression results respectively.

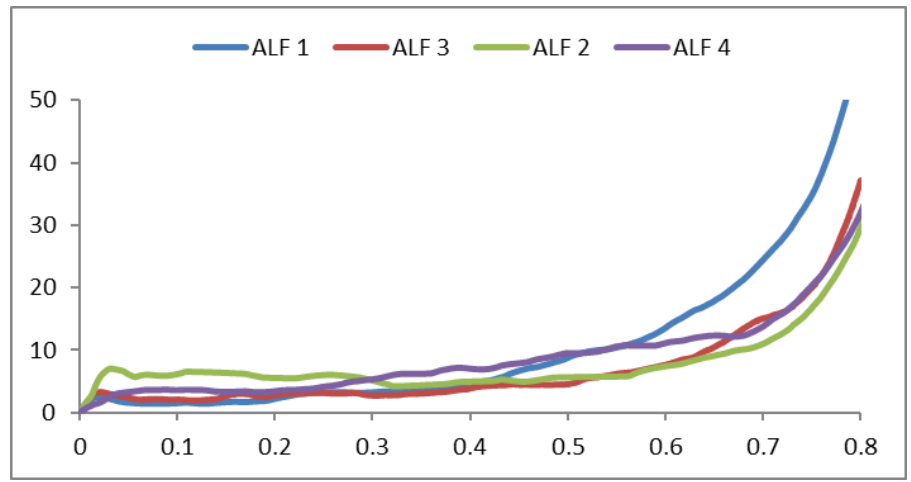

Fig. 1. Deformation behavior of respective foams

\subsection{Finite Element Modeling of Square Tube}

Three dimensional (3D) finite element models were created using shell elements available in the commercially available FEM software, Abaqus 6.13 [19]. The shell column wall was modeled with S4R elements: A 4-noded doubly curved shell element with reduced integration, hourglass control, and finite membrane strains. The cross section of the square tube is $80 \mathrm{~mm} \times 80 \mathrm{~mm}$ size; a column of height $245 \mathrm{~mm}$, and a thickness of $1 \mathrm{~mm}$. The cross section details and FEM model can be seen in Fig. 2 [13]. Clamped boundary condition was applied at the bottom of the column. Ten different cases have been considered in the present numerical simulation as shown in Table 2. Initially, two empty square tube simulations were carried out using Al-2014 and MSrst37 alloy materials in the shell column wall, and then both the square tubes were in-filled with four different types of foams as described in Table 1 and Table 2. Further the present work has been extended to study the effect of coefficient of friction on the square tube in terms of energy absorption.

To replicate the actual hitting of car, a $1000 \mathrm{~kg}$ inertia mass and velocity of $36 \mathrm{~km} / \mathrm{hr}$ is applied on the top of the square tube to generate enough kinetic energy corresponds to the velocity of car running at $36 \mathrm{~km} / \mathrm{hr}$ (Fig. 1). The strengthening interaction between the shell column wall and in-filled foam was simulated with a surface-to-surface tie contact. During the formation of shell column folding, inter-penetration between two folds of the column wall was prevented by using self-contact algorithm available in Abaqus (Abaqus 2013). In the above study the coefficient of friction between shell column wall and in-filled foam is taken as 0.2 . While studying the effect of coefficient of friction it varied from 0.2 to 0.8 . In all the cases non linear FEM analyses was performed using dynamic explicit solver available in Abaqus. The constitutive behavior of 
the thin shell element for the column material was based on the elastic-plastic material model with Von Mises's isotropic plasticity algorithm. In the FEM analysis, the stress-strain curves of the foams have been taken from the referred literature as mention in Table 1.
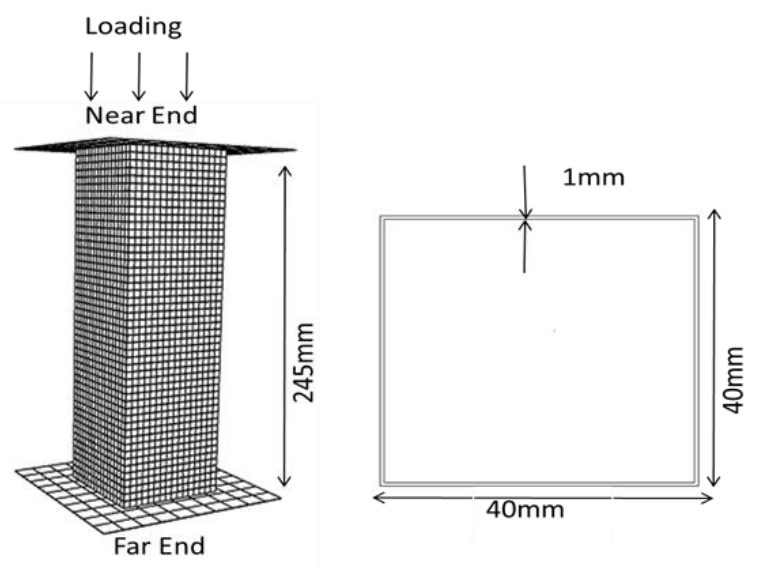

Fig. 2. 3D finite element modelling of crash box.

Table 1. Properties and Symbol of Shell Column and In-filled Foam Materials

\begin{tabular}{|c|c|c|c|c|c|}
\hline Material & Type & Symbol & $\begin{array}{l}\text { Density of foam } \\
\text { (gm/cc) }\end{array}$ & $\begin{array}{c}\text { Young's } \\
\text { Modulus (MPa) }\end{array}$ & $\begin{array}{l}\text { Poison's } \\
\text { Ratio }\end{array}$ \\
\hline $\mathrm{Al}-2014[20]$ & Solid & $\mathrm{Al}$ & 2.8 & 70.30 & 0.3 \\
\hline MSrst37 [13] & Solid & MS & 7.8 & 210.00 & 0.3 \\
\hline ALSi8Mg foam [13] & Foam & ALF1 & 0.200 & 384.08 & 0.0 \\
\hline CYMAT Al-SIC foam [21] & Foam & ALF2 & 0.270 & 1069.33 & 0.0 \\
\hline $\begin{array}{l}\text { Duocel Al-6106-T6 foam, } \\
7.56 \% \text { relative density } 1 \text { [23] }\end{array}$ & Foam & ALF3 & 0.204 & 400.07 & 0.0 \\
\hline $\begin{array}{l}\text { Duocel Al-6106-T6 foam, } \\
8.7 \% \text { relative density [23] }\end{array}$ & Foam & ALF4 & 0.235 & 529.83 & 0.0 \\
\hline
\end{tabular}

\section{Validation}

The present numerical methodology has been validated on mild steel (MSrst37) alloy, using the experimental results and also from the literature [22]. In this a square tube of $40 \mathrm{~mm} \times 40 \mathrm{~mm}$ cross section and of $1.4 \mathrm{~mm}$ thickness has been tested under compressive loading condition. The height of the square tube was $150 \mathrm{~mm}$. This was made up of mild steel (MSrst37) alloy as used in the present study in some of the cases. To validate the experimental result an FEM model of the above geometric details has been prepared using Abaqus software. Fig. 3 showed the comparison of FEM predicted deformation behavior of square tube and the corresponding experimental results. It can be seen that the two results are comparable with each other with a slight variation in the initial region. This may have come as the source of material data of the square tube [22] is different from that of compressive stress-strain curve [13] used as an input in the FEM analysis. Thus the present numerical methodologies used in the modeling of foam in-filled square tubes have been validated with the experiment results. 


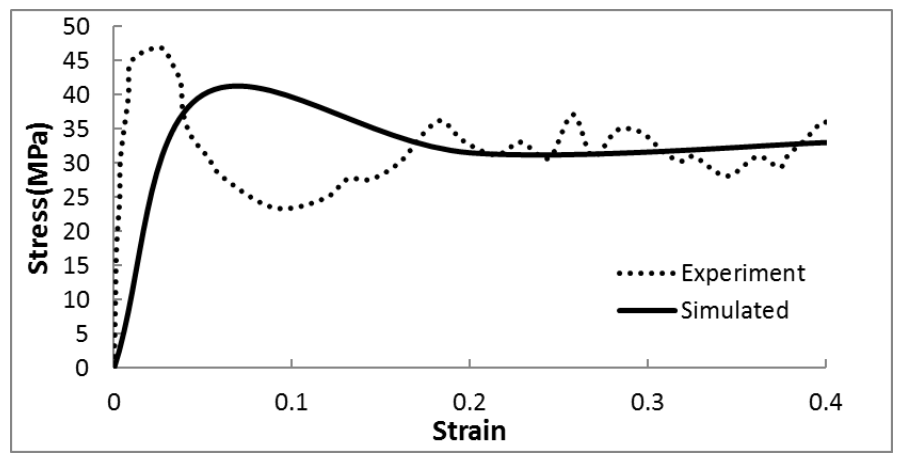

Fig. 3. Validation of numerical results with experiment.

\section{Results and Discussion}

In the present study, aluminum alloy (Al-2014) and mild steel (MSrst37) empty square tubes have been considered. Fig. 4((a) \& (b)) showed the folding pattern obtained in the FEM analysis of two empty square tubes. Other than this, Fig. 4((a) \& (b)) showed the folding patter of foam in-filled square tubes having Al2014 and MSrst37 materials in the shell column wall. In the present study, the numerical results obtained at $100 \mathrm{MPa}$ have been discussed. At $100 \mathrm{MPa}$ stress level, total deformation of empty and foam in-filled square tubes reached the densification stage in all the cases considered.

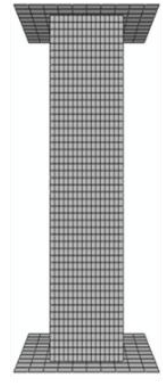

$30 \mathrm{~mm}$

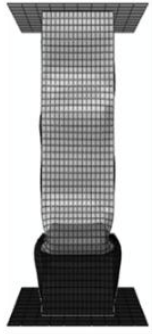

$90 \mathrm{~mm}$

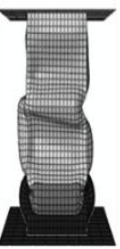

(a)

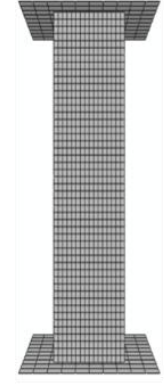

$30 \mathrm{~mm}$

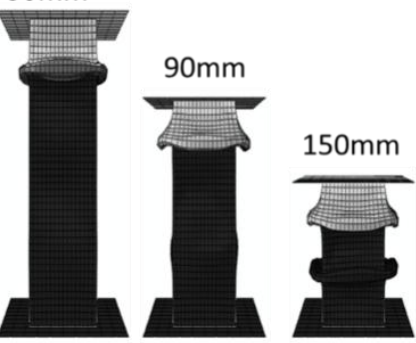

(b)

Fig. 4. Deformation stages of empty crash boxes: (a) Al-2014; (b) MSrst37.

\subsection{Deformation of Empty Square Tubes}

In case of aluminum (AL-2014) empty square tube as shown in the Fig. 4(a), at $30 \mathrm{~mm}$ displacement, the shell column wall started buckling from the far end whereas in case of mild steel (Fig. 4(b)), outward buckling started at the near end thus protecting the far end of the square tube and other car components from damaging. The difference in the two deformation behavior may be due to the difference in the density of two materials. In case of empty square tube, higher density material (MSrst37) is giving better initial buckling behavior as compared to lighter material (Al-2014). In case of Al-2014, at $90 \mathrm{~mm}$ displacement, second fold started at the mid portion whereas in MSrst37 case, outward buckling started at near end which is desirable to avoid damage of components near chassis. At $150 \mathrm{~mm}$ displacement, in case of Al2104, the square tube collapse almost with deformation accompanied by inward and outward folding. There are only two folds in case of MSrst37 square tube at $150 \mathrm{~mm}$ displacement, with stable column in the middle. Both the square tube collapsed completely at $200 \mathrm{~mm}$ displacement. There are inward and outward folding pattern observed in case of Al-2014, whereas only outward buckling seen in case of MSrst37.

Fig. 6 showed the deformation behavior of the two empty square tubes considered in the present analysis (Table 2). As can be seen, empty square tubes have linear elastic, plateau region and also the densification 
region same as in the foam behavior. It can be seen that the deformation behavior of empty square tubes under compressive loading are almost same. The difference of energy absorption capacity between these two empty square tube was found to be only $1.5 \%$. In consideration with only small difference in energy absorption capacity, it can be concluded that the only benefit of using heavier empty crack box of MSrst37 is to have better deformation pattern under car accident condition as compared to empty Al-2014 square tube.

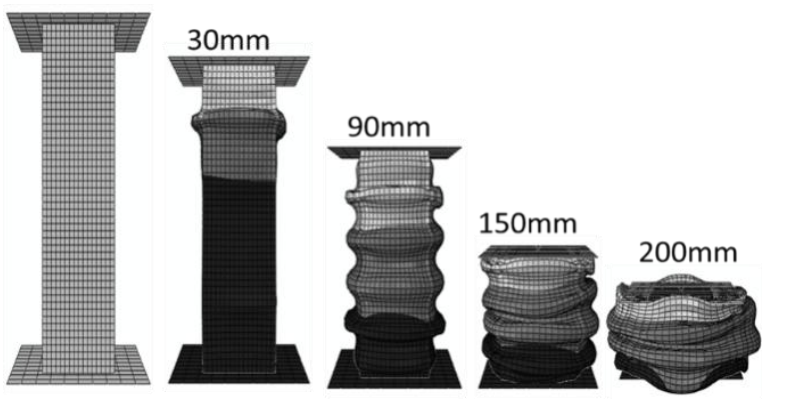

(a)

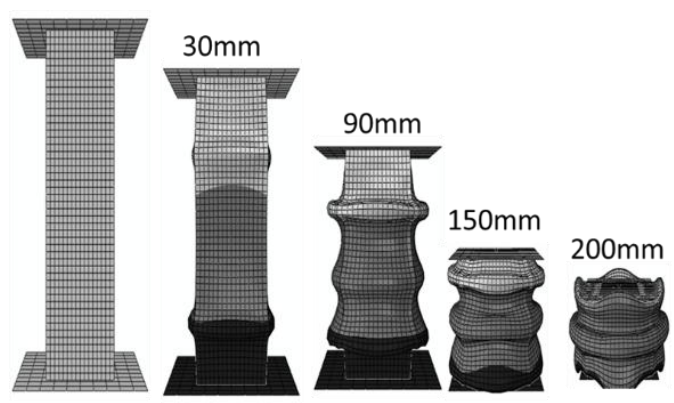

(b)

Fig. 5. Deformation stages of foam in-filled crash boxes: (a) Al-ALF2; (b) MS-ALF2.

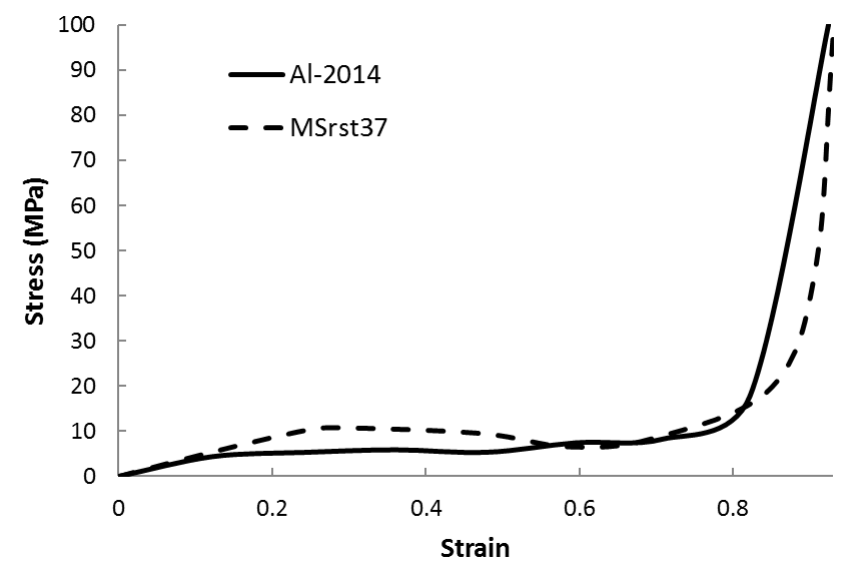

Fig. 6. Deformation behavior of empty crash boxes.

Table 2. Comparison of Results in Different Cases Considered

\begin{tabular}{cccc}
\hline Crash Box & Type & Energy Absorption $\left(\mathbf{1 0}^{-3} \mathbf{J}\right)$ & SEA Capacity $\left(\mathbf{1 0}^{-3} \mathbf{J} / \mathbf{K g}\right)$ \\
\hline \multirow{4}{*}{ Al-2014 } & Empty & 11.32 & 54.15 \\
& Al-ALF1 & 18.50 & 88.50 \\
& Al-ALF2 & 26.45 & 126.53 \\
& Al-ALF3 & 18.19 & 87.02 \\
& Al-ALF4 & 21.44 & 102.57 \\
\hline \multirow{3}{*}{ MSrst37 } & Empty & 11.15 & 53.34 \\
& MS-ALF1 & 22.06 & 105.51 \\
& MS-ALF2 & 29.89 & 142.99 \\
& MS-ALF3 & 19.20 & 91.85 \\
& MS-ALF4 & 21.68 & 103.72 \\
\hline
\end{tabular}




\subsection{Deformation of Foam In-filled Square Tube}

Fig. 5 (a) shows the buckling pattern of foam in-filled Al-ALF2 square tube. Compared to the empty Al2014 square tube, the deformation behavior of the foam in-filled square tube was considerably different. In case of Al-ALF2 foam in-filled square tube, at $30 \mathrm{~mm}$ displacement, the outward buckling started from the near end similar to the case of empty MSrst37 square tube, which is desirable to protect the components at the other end from damage. This foam in-filled behavior of Al-ALF2 is different than the case of empty Al2104 square tube (Fig. 4(a)), where outward buckling started at far end. Due to the presence of foam in the square tube, these outward buckling provide the resistance to the square tube during the folding process. Thus it clearly shows the importance of foam in-filling is improving the initial deformation pattern of square tube in case of aluminum 2014 alloy. In case of MS-ALF2, at $30 \mathrm{~mm}$ displacement, two outward buckling folds can be seen in Fig. 5(b). Thus at the initial stage, the effect of foam inclusion in MS-ALF2 is not so favorable. This may be due to the difference in density of MSrst37 shell column wall and aluminum in-filled foam material. In case of Al-ALF2, at $90 \mathrm{~mm}$ displacement, five outward folds formed whereas in MS-ALF2 case, only three outward folds were formed, thus showed more deformation in the case of Al-ALF2 as compared to MS-ALF2. At $150 \mathrm{~mm}$ displacement, in case of Al-ALF2, the square tube collapse plastically with deformation accompanied by five outward folding whereas MS-ALF2 collapsed with four outward folding. Both the square tube collapsed completely at $200 \mathrm{~mm}$ displacement with more outflow deformation of shell column wall material as compared to empty square tube. Fig. 7 (a) showed the deformation behavior curves of $\mathrm{Al}-2014$ foam in-filled square tubes. The energy absorbed by Al-ALF2 square tube is 1.4 times more than the empty Al-2014 square tube (Table 2). As can be seen in Table 2, the maximum energy absorbed in case of foam in-filled aluminum shell column material is Al-ALF2 and the minimum energy absorbed is Al-ALF3. It can be seen in the result that Al-ALF2 square tube absorbs $45.4 \%$ more energy as compared to Al-ALF3 square tube (Table 2). In case of foam in-filled mild steel shell column wall, MS-ALF2 case absorbs 2.68 times more energy as compared to empty mild steel shell column case (Fig. 7(b)). Among foam in-filled mild steel cases, MS-ALF2 absorbs maximum energy, and MS-ALF3 absorbs the minimum energy. MS-ALF2 foam in-filled case absorbs $55.68 \%$ more energy as compared to MS-ALF3. Among all the foam in-filled cases considered in the present study with Al or MS shell column wall, MS-ALF2 absorbs maximum energy. The energy absorbed by MS-ALF2 is 13\% more than Al-ALF2. Thus considering energy absorption capacity, it can be concluded that MS-ALF2 is best among all the cases considered in the present study but in terms of folding pattern, deformation behavior and also being light weight, Al-ALF2 is better than MS-ALF2. Fig. 8 showed the comparison of deformation behavior and energy absorption capacity of empty and foam in-filled best performed square tubes (MS-ALF2 and AL-ALF2).

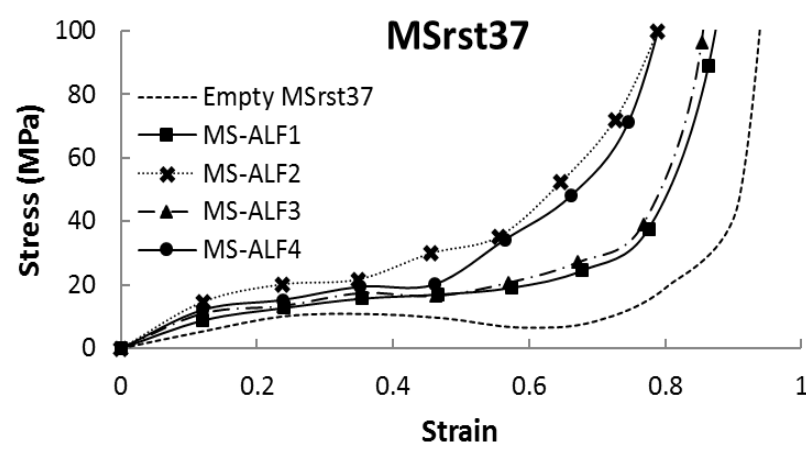

(a)

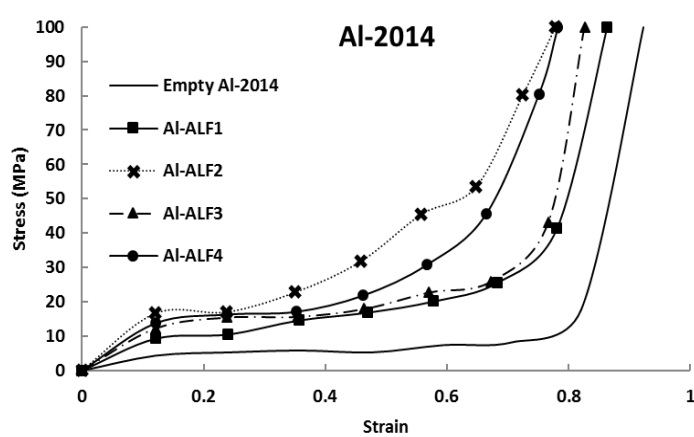

(b)

Fig. 7. Deformation behavior of foam in-filled crash boxes: (a) Al-2014; (b) MSrst37. 


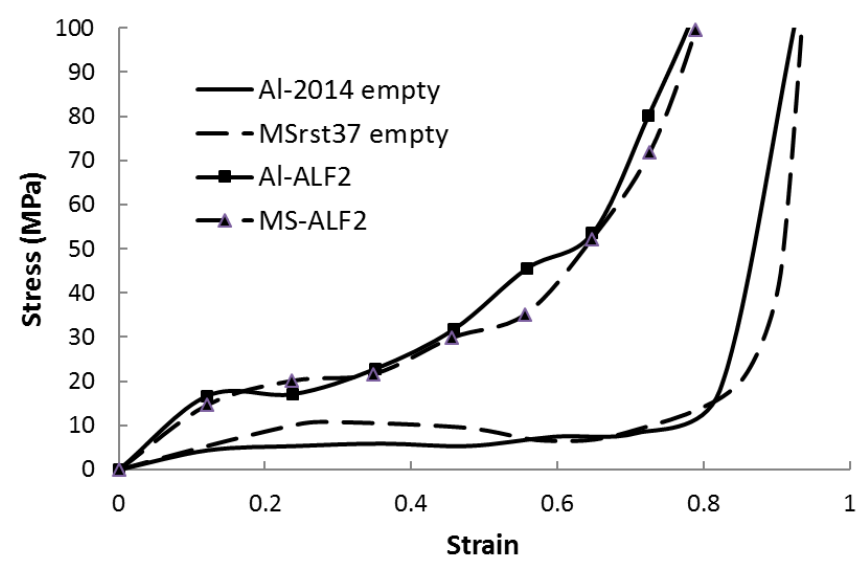

Fig. 8. Comparison of compression behavior of empty and foam in-filled crash boxes.

\subsection{Comparison in terms of Specific Energy Absorption (SEA)}

The energy absorption capacity of square tube is also quantified in terms of specific energy absorption (SEA) capacity [24] which is defined as:

$$
S E A=\frac{E_{\text {total }}}{M_{\text {total }}}
$$

where $E_{\text {total }}$ denotes the total energy absorption and $M_{\text {total }}$ denotes the total mass of the square tube. Table 2 showed the SEA values for all the cases of the square tubes studied in the present study. In spite of the large density difference between the two shell column materials, both the empty square tubes have nearly same specific energy absorption capacity with a difference of $1.5 \%$ only. In case of foam in-filled square tubes, MS-ALF2 outperformed with SEA of $142.99 \mathrm{~mJ} / \mathrm{Kg}$ followed by Al-ALF2. This may be due to the complex interaction mechanism between shell column wall and the in-filled foam during the deformation process. It come out that higher density of shell column material used with aluminum in-filled foam filling absorbs maximum specific energy as compared to lighter shell column material. Though the MS-ALF2 does not give better folding pattern initially but specific energy absorption is maximum among all the cases considered.

\subsection{Effect of Coefficient of Friction in Square Tube Performance}

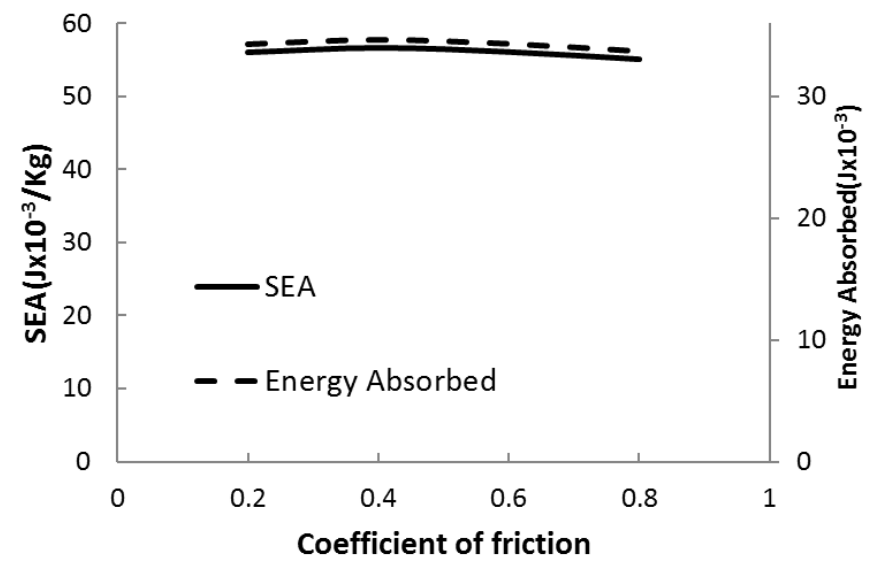

Fig. 9. Effect of coefficient of friction between shell column wall and in-filled foam. 
In the present study, the effect of varying the coefficient of friction between shell column wall and in-filled foam has been studied. The study has been conducted using the best performed square tube obtained in the present study i.e. MS-ALF2 (Table 2). The effect of coefficient of friction has been assessed in terms of both, the energy absorbed and the SEA capacity as shown in Fig.9. It can be seen at there is no significant change in energy absorption capacity and SEA capacity due to the change in coefficient of friction when varying from 0.2 to 0.8 . Therefore, it can be concluded that in such a case of car hitting, the effect of coefficient of friction between shell column wall and in-filled foam is negligible.

\section{Conclusions}

In the present study, ten different cases of empty and foam in-filled square tubes have been considered (Table 2). They have been evaluated under car accidental condition in terms of deformation pattern, energy absorption and specific energy absorption. The effect of coefficient of friction between shell column wall and in-filled foam has also been evaluated. The following conclusion can be drawn:

- The deformation behavior of empty square tube is similar to that of foam with linear, plateau region and densification region.

- In empty square tube of aluminum shell column wall, there is an inward-outward folding pattern, whereas in mild steel shell column wall, it is outward buckling pattern.

- The stress strain deformation behavior of aluminum and mild steel empty square tube is almost same (differ by $1.5 \%$ ) though there is a high difference in the two material densities.

- The initial folding pattern of mild steel shell column wall empty square tube is better than aluminum case, due to higher density of mild steel material.

- Among all the foam in-filled square tubes, MS-ALF2 case (MS shell column material with ALF2 foam in-filled) absorbs maximum energy. Thus it comes out that higher density of shell column material (MS) with aluminum in-filled foam square tube absorbs maximum energy as compared to lighter material shell column wall.

- Aluminum shell column wall material with aluminum in-filled foam square tube AL-ALF2 showed better folding pattern and it is also lightweight but showed 13\% lower energy absorption capacity than MS-ALF2 foam in-filled square tube.

- The effect of coefficient of friction between shell column wall and in-filled foam is negligible in the case of car accident as consider in the present study.

\section{References}

[1] Yu, S. R., Liu, J. A., Wei, M., Luo, Y. R., Zhu, X. Y., \& Liu, Y. H. (2009). Compressive property and energy absorption characteristic of open-cell ZA22 foams. Materials \& Design, 30(1), 87-90.

[2] Meguid, S. A., Attia, M. S., \& Monfort, A. (2004). On the crush behavior of ultra light foam-filled structures. Materials \& Design, 25(3), 183-189.

[3] Meguid, S. A., Stranart, J. C., \& Heyerman, J. (2004).On the layered micromechanical three-dimensional finite element modelling of foam-filled columns. Finite Elements in Analysis \& Design, 40(9-10),10351057.

[4] Hanssen, A. G., Langseth, M., \& Hopperstad, O. S. (2000). Static and dynamic crushing of circular aluminum extrusions with aluminum foam filler. International Journal of Impact Engineering, 24(5), 475-507.

[5] Hanssen, A. G., Langseth, M., \& Hopperstad, O. S. (2000). Static and dynamic crushing of square aluminium extrusions with aluminium foam filler. International Journal of Impact Engineering, 24(4), 347-383.

[6] Hanssen, A. G., \& Langseth M. (1996). Development in aluminum based crash absorption components. Proceedings of the Norwegian-French Industrial Conference. Paris.

[7] Hanssen, A. G., Langseth, M., \& Hopperstad, O. S. (1999). Static crushing of square aluminium 
extrusions with aluminium foam filler. International Journal of Mechanical Sciences, 41(8), 967-993.

[8] Wang, Q., Fan, Z., \& Gui, L. (2006). A theoretical analysis for the dynamic axial crushing behaviour of aluminium foam-filled hat sections. International Journal of Solids and Structures, 43(7), 2064-2075.

[9] Webb, D. C., Webster, J., \& Kormi, K. (2001) Finite element simulation of energy absorption devices under axial static compressive and impact loading. International Journal of Crashworthiness, 6(3), 399424.

[10] Santosa, S., \& Wierzbicki, T. (1998). Crash behavior of box columns filled with aluminum honeycomb or foam. Computers \& Structures, 68(4), 343-367.

[11] Huang, X., \& Lu, G. (2003). Axisymmetric progressive crushing of circular tubes. International Journal of Crashworthiness, 8(1), 87-95.

[12] Hanssen, A. G., Lorenzi, L., Berger, K. K., Hopperstad, O. S., \& Langseth, M. (2000). A demonstrator bumper system based on aluminium foam filled crash boxes. International Journal of Crashworthiness, 5(4), 381-392.

[13] Guo, L. W., Yu, J. L., \& Li, Z. B. (2010). Experimental studies on the quasi-static bending behavior of double square columns filled with aluminum foams. Acta Mech., 213(3), 349-358.

[14] Santosa, S., \& Wierzbicki, T. (1998). Crash behavior of box columns filled with aluminum honeycomb or foam. Computers \& Structures, 68(4), 343-367.

[15] Sigit, S., \& Tomasz, W. Effect of an ultralight metal filler on the torsional crushing behaviour of thinwalled prismatic columns. International Journal of Crashworthiness, 1997, 2(4), 305-332.

[16] Santosa, S., \& Wierzbicki, T. (1999). Effect of an ultralight metal filler on the bending collapse behavior of thin-walled prismatic columns. International Journal of Mechanical Sciences, 41(8), 995-1019.

[17] Abramowicz, W., \& Wierzbicki, T. (1988). Axial crushing of foam-filled columns. International Journal of Mechanical Sciences, 30(3-4), 263-271.

[18] Abaqus 6.13 Documentation. (2013). http://129.97.46.200:2080/v6.13/.

[19] Mondal, D. P., Jha, N., Badkul, A., Das, S., \& Khedle, R. (2012). High temperature compressive deformation behaviour of aluminum syntactic foam. Materials Science \& Engineering A, 534, 521-529.

[20] Chen, W. G. (2001). Experimental and numerical study on bending collapse of aluminum foam-filled hat profiles. International Journal of Solids and Structures, 38(44), 7919-7944.

[21] Seitzberger, M., Rammerstorfer F. G., Degischer, H. P., Gradinger, R. (1997). Crushing of axially compressed steel tubes filled with aluminum foam. Acta Mechanica, 125(1-4), 93-105.

[22] Energy absorption. Retrieved from http://www.ergaerospace.com/Energy-Absorbtion.html.

[23] Kim, H. S. (2002). New extruded multi-cell aluminum profile for maximum crash energy absorption and weight efficiency. Thin-walled Structures. 40(4), 311-327 .

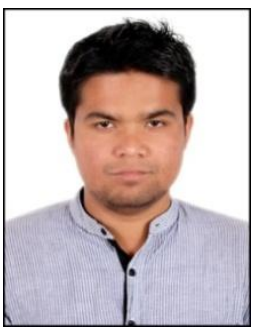

Rana Pratap Singh is a post graduate student in material science engineering at IIT Gandhinagar . He received his first degree from NIT Raipur awarded with a Bachelor of Technology in Metallurgical engineering. His research area includes powder metallurgy, metal matrix composites, aluminium foam and electrochemistry

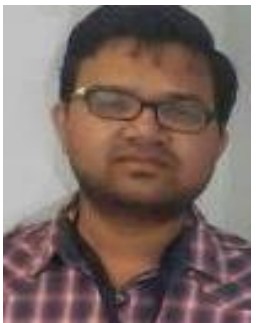

Gaurav Kumar Gupta is a scientist at CSIR-AMPRI in Light weight Materials and Metal composite group. Mr Gupta received his education in Metallurgy and material science from IIT Kanpur, India. To date, he has published several scientific articles related to the Material science engineering field .Mr Gupta's research has been focused on material processing through powder metallurgy and novel processing methods to enhance its properties. 